\title{
Multiscale computation of solar radiation for predictive vegetation modelling
}

\author{
Christian PIEDALlU*, Jean-Claude GÉGOUT \\ AgroparisTech-ENGREF, LERFoB UMR INRA-ENGREF 1092 - Équipe Écologie Forestière, 14 rue Girardet, 54042 Nancy Cedex, France
}

(Received 12 February 2007; revised version 29 May 2007; accepted 4 July 2007)

\begin{abstract}
The recent development of large environmental databases allow the analysis of the ecological behaviour of species or communities over large territories. Solar radiation is a fundamental component of ecological processes, but is poorly used at this scale due to the lack of available data. Here we present a GIS program allowing to calculate solar radiation as well locally as at large scale, taking into account both topographical (slope, aspect, altitude, shadowing) and global (cloudiness and latitude) parameters. This model was applied to the whole of France $\left(540000 \mathrm{~km}^{2}\right)$ for each month of the year, using only a 50-m digital elevation model (DEM), latitude values and cloudiness data. Solar radiation measured from 88 meteorological stations used for validation indicated a $R^{2}$ of 0.78 between measured and predicted annual radiation with better predictions for winter than for summer. Radiation values increase with altitude, and with slope for southern exposure, excepted in summer. They decrease with latitude, nebulosity, and slope for north, east, and west exposures. The effect of cloudiness is important, and reduces radiation by around $20 \%$ in winter and $10 \%$ in summer. Models of plant distribution were calculated for Abies alba, Acer pseudoplatanus, and Quercus pubescens, for France. The use of solar radiation improved modelling for the three species models directly or through the water balance variable. We conclude that models which incorporates both topographical and global variability of solar radiation can improve efficiency of large-scale models of plant distribution.
\end{abstract}

solar radiation / water balance / geographical information system (GIS) / digital elevation model (DEM) / plant distribution models / vegetation modelling

Résumé - Calcul multi-échelle du rayonnement solaire pour la modélisation prédictive de la végétation. Le développement récent d'importantes bases de données phytoécologiques permet l'analyse du comportement des espèces ou des communautés sur de larges territoires. Le rayonnement solaire est une composante essentielle du fonctionnement des écosystèmes, mais il est peu utilisé à cette échelle du fait du manque de données disponibles. Nous présentons un programme élaboré sous SIG permettant de calculer le rayonnement aussi bien localement que sur de vastes espaces, prenant à la fois en compte des paramètres locaux (pente, exposition, altitude, effet de masque) et globaux (latitude, nébulosité). Ce modèle a permis de calculer le rayonnement solaire sur l'ensemble de la France $\left(540000 \mathrm{~km}^{2}\right)$, pour chaque mois de l'année, en utilisant seulement un Modèle Numérique de Terrain (MNT) de $50 \mathrm{~m}$ de résolution, des valeurs de latitude et des données de nébulosité. Les radiations solaires de 88 postes météorologiques ont été utilisées pour la validation, le $R^{2}$ entre le rayonnement annuel prédit par le modèle et celui mesuré sur les postes météorologiques s'établissant à 0,78 , avec de meilleures prédictions pour l'hiver que pour l'été. Les valeurs de radiations augmentent avec l'altitude, et la pente pour les expositions sud, hormis en été. Elles diminuent avec la latitude, la nébulosité, et la pente pour les expositions nord, est et ouest. L'effet de la nébulosité est important et réduit le rayonnement d'environ $20 \%$ en hiver et $10 \%$ en été. Des modèles de distribution ont été calculés pour trois essences, Abies alba, Acer pseudoplatanus, et Quercus pubescens, pour la France. L'utilisation du rayonnement solaire améliore les trois modèles, directement ou à travers la variable de bilan hydrique. Nous concluons qu'un modèle de rayonnement solaire qui inclut à la fois la variabilité topographique et des facteurs plus globaux, est approprié pour améliorer l'efficacité des modèles de distribution des plantes réalisés à large échelle.

rayonnement solaire / bilan hydrique / système d'information géographique (SIG) / modèle numérique de terrain (MNT) / modèles de distribution des plantes / modélisation de la végétation

\section{INTRODUCTION}

Solar radiation plays a paramount role in the distribution, composition, and productivity of ecosystems through photosynthesis and the water cycle. Solar radiation contributes to several parameters of the water balance (air and soil heating, evapotranspiration, winds, snow and ice melt), and represents a direct resource gradient [1], which is related to vegetation processes. It is thus not surprising that many studies try to link solar radiation to the distribution of plant species $[3,9,21,31$, $32,36]$. However, studies using solar radiation generally con-

\footnotetext{
*Corresponding author: Piedallu@engref.fr
}

cern limited areas (from a few hectares to hundreds of square kilometres), due to the difficulty of accurately computing local and larger-scale radiation.

Solar radiation is measured directly at ground meteorological stations. Data can be interpolated to larger areas [25,47], but the limited number of meteorological stations recording this parameter, and the strong variability due to topography, have hampered the drawing of accurate radiation maps [17, 23]. Satellite data, such as that of Meteosat, AVHRR or GOES, allow a spatial approach to vast territories, but the values do not take into account topographic variability [23].

Since the early 1990s, geographical information systems (GIS) technology has enabled researchers to develop 
several models of solar radiation. The "ATM" [13] and "Solarflux" [22] models were the first developed, and were followed by others such as "Shortwave" and "Direct" [30], "Solar Analyst" [17], "Toporad" [26], "SRAD" [53], "FORGAP" [52], and "r.sun" [23]. These models adopt different methods of calculating radiation, but their use makes possible a great quantity of calculations, they are cost-efficient, well suited to topographically complex areas, and accurate $[14,46]$. The data can be calculated with high resolution, according to the digital elevation model (DEM).

With the development of large databases $[4,19]$ and methods of sampling [15], vegetation studies require accurate environmental data over larger and larger areas in order to model species distribution on the scale of their distribution area [20]. At broad scale, radiation calculation need to combine smallscale variability caused by topographic variations and largescale modulators like latitude or cloudiness [11]. Some of the existing programs are not suited to large scale calculations because they only provide clear sky radiations, or they considered latitude as constant value [17,30]. Other models used more elaborated methods of calculation, but they require many parameters difficult to spatially estimate and not always available on the study site like sunshine fraction, albedo, min and max air temperature, or atmospheric transmittance [26, 53]. This problem of input availability is accentuated when studies overlay different countries, generally having heterogeneous ground meteorological datasets. If the improvement in computing capacity now allows national or continental solar radiation calculations at fine resolution, this limitations of current models explain they are actually poorly used in large-scale plant distribution modelling. If many studies established importance of solar radiation at local scale [24,29], its ability to improve plant distribution model at large scale is actually weakly known.

The aim of this study was to :

- Present a new GIS based program, called Helios, allowing to easily calculate accurate solar radiation values, useful to predict plant distribution as well locally as for broad scales. This program must require few input parameters, largely available over the world.

- Validate the solar radiation computation over a large area.

- Evaluate the ability of calculated solar radiation to improve large scale plant distribution models.

The Helios program has been developed linked with ArcInfo, one of the most popular GIS software packages. The calculation combines local topographical (slope, aspect, shadowing) and global (cloudiness and latitude) parameters, allowing to estimate solar radiation whatever the scale. It requires only the use of a digital elevation model and values of cloudiness. These data are freely available on the web for most of the countries. The values of cloudiness, which are classical measures, can also be interpolated from meteorological stations.

The radiation model was implemented for France at the finest available resolution covering the whole country $(50 \times$ $50 \mathrm{~m}$ spaced grid). To assess their quality, modelled radiation data were compared to measured data in 88 meteorological stations scattered over the country. We then evaluated the sen- sitivity of the model on different geographical scales according to slope, aspect, altitude, latitude or cloudiness. Finally, we modelled the distribution of three plant species (Abies alba, Quercus pubescens, and Acer pseudoplatanus), in order to evaluate the ability of Helios to improve plant distribution models.

\section{METHODS}

\subsection{Model description}

Shortwave radiation covers the $0.28-5 \mu \mathrm{m}$ range of the spectrum, they can be separated into three components $[12,18]$ : direct radiation from the sun, which is generally the greatest; diffuse sky radiation, which is diffused by the atmosphere and depends on its composition, and terrain-reflected radiation, which is the part of the direct or diffuse radiation scattered by the ground. This component is a function of the ground cover, and can be large for snow-covered areas because of high albedo.

The amount of global radiation is obtained by summation of the direct, diffuse and terrain-reflected components at the earth's surface. They are determined by three groups of factors: geometric relations between the sun and the earth's surface, atmospheric attenuation and topographic factors $[18,23,46,52]$.

Geometric relations between the sun and the earth's surface are characterised by the earth's geometry, revolution, and rotation, that can be calculated with astronomic formulas. This explains the global scale latitudinal gradient observed with vegetation.

Atmospheric attenuation is due to gases, solid and liquid particles. Extraterrestrial solar radiation is attenuated according to the thickness of the atmosphere, and calculated according to altitude. It can be determined with a good level of precision.

Topographic factors induce strong variations on a local scale, due to surface orientation and surface inclination, which modify the angle of incidence of insolation [18]. On the other hand, sky obstruction by surrounding topography, which can be simulated with a DEM, can limit direct radiation in mountainous terrain by shadowing. These factors can be modelled with high accuracy, depending on the resolution of the DEM.

Attenuation by clouds is considered separately. It can provide from different sources of data [11]. We used empirical equations based on extrapolation of average monthly cloudiness measured at ground meteorological stations [27].

\subsubsection{Earth-sun geometry}

Sun position in the sky is a function of the time and latitude [18]. At the beginning of the process, a grid with latitude values for each pixel is generated, which enables the use of latitude as a variable during all of the calculations. Sun position is defined by its solar altitude solar azimuth angles.

Solar altitude angle $(\alpha)$ defines the elevation of the sun above the horizon for a location:

$$
\sin \alpha=\sin \varphi \times \sin \delta+\cos \varphi \times \cos \eta \times \cos \delta
$$

where $\varphi$ is latitude calculated for the studied cell, $\eta$ is hour angle, (i.e. the angular distance between the sun and the local meridian line), $\delta$ is solar declination, the angle between the solar beam and the equatorial 
Table I. Parameters and references used in Helios program.

\begin{tabular}{|c|c|c|c|}
\hline Parameters & Abbreviation & Value & References \\
\hline \multicolumn{4}{|l|}{ Earth-sun geometry } \\
\hline Solar altitude angle & $\alpha$ & & Gates, 1980 \\
\hline Latitude & $\varphi$ & & \\
\hline Hour angle & $\eta$ & & \\
\hline Solar declination & $\delta$ & & Cooper, 1969 \\
\hline Day number & $\mathrm{J}$ & & \\
\hline Solar azimuth & $\beta$ & & Oke, 1987 \\
\hline \multicolumn{4}{|l|}{ Light characteristics and extinction } \\
\hline Solar flux outside the atmosphere & Rout & & Kreith and Kreider, 1978 \\
\hline Solar constant & $S c$ & $1367 \mathrm{~W} / \mathrm{m}^{2}$ & \\
\hline Coefficient of transmissivity & $\tau^{\mathrm{M}}$ & $\tau=0.6$ & Gates, 1980 \\
\hline Length of the path & M & & Kreith and Kreider, 1978 \\
\hline Atmospheric pressure & $P / P 0$ & & List, 1984 \\
\hline Altitude & $h$ & & \\
\hline Relative path length of the optical air mass at sea level & Mo & & Kreith and Kreider, 1978 \\
\hline \multicolumn{4}{|l|}{ Topographical effects } \\
\hline Angle of incidence & $\cos i$ & & Campbell, 1981 \\
\hline Slope $\left({ }^{\circ}\right)$ & $\chi$ & & \\
\hline Aspect $\left({ }^{\circ}\right)$ & $\beta s$ & & \\
\hline \multicolumn{4}{|l|}{ Global radiation calculation } \\
\hline Direct radiation & Rdir & & Gates, 1980 \\
\hline Binary value of shadowing & $S h$ & & \\
\hline Diffuse radiation & Rdiff & & Liu and Jordan, 1960 \\
\hline Terrain-reflected irradiance & Rreff & & Gates, 1980 \\
\hline Reflectance of the ground surface & $r$ & 0.2 & \\
\hline Global radiation & Rtot & & Gates, 1980 \\
\hline \multicolumn{4}{|l|}{ Overcast calculation } \\
\hline Cloud attenuation factor & $K c$ & & Kasten and Czeplak, 1980 \\
\hline Overcast radiation & Rtotc & & \\
\hline Cloudiness (Oktas) & $N$ & & \\
\hline
\end{tabular}

plane, varying depending on day number $J$ [6] (all formulas parameters and their abbreviations are resumed in Tab. I):

$$
\delta=23.45 \times \sin (360(284+J) / 365) .
$$

Solar azimuth $(\beta)$ is the angle between the sun and true north. Oke's [41] formula was used:

$$
\cos \beta=(\sin \delta \times \cos \varphi-\cos \delta \times \sin \varphi \times \cos \eta) / \cos \alpha .
$$

\subsubsection{Light characteristics and extinction}

We calculated the solar flux outside the atmosphere $\left(\right.$ Rout, $\left.\mathrm{W} / \mathrm{m}^{2}\right)$ with the model of Kreith and Kreider [28]. Solar flux is a function of solar constant Sc (we used the World Radiation Center value of $\left.1367 \mathrm{~W} / \mathrm{m}^{2}\right)$, and the day of year $(J)$ :

$$
\text { Rout }=S c \times(1+0.034 \times \cos (360 J / 365)) .
$$

The coefficient of transmissivity $\tau^{\mathrm{M}}$ represents the fraction of incident radiation at the top of the atmosphere which reaches the ground along a vertical trajectory. We chose a value of 0.6 for $\tau$ [18]. $M$ represents the length of the path according to the solar azimuth. In mountainous areas it is necessary to use a correction factor related to the atmospheric pressure $P / P o$, which depends on altitude. We used the formulas of List [33] and Kreith and Kreider [28]:

$$
M=M o \times P / P o
$$

$\mathrm{P} / \mathrm{Po}$ (mbar/mbar) is the correction of the atmospheric pressure calculated as follows:

$$
P / P o=((288-0.0065 \times h) / 288)^{5.256}
$$

where $h$ is altitude.

$M o$ is the relative path length of the optical air mass at sea level:

$$
\text { Mo }=\sqrt{1229+(614 \times \sin \alpha)^{2}}-614 \times \sin \alpha .
$$

\subsubsection{Topographical effects}

To calculate radiation on tilted surfaces, it is necessary to define the angle of incidence ( $\cos i$ ) between the incoming solar ray and the 
surface of the ground. It varies with sun position and topographical conditions [5]:

$$
\cos i=\cos \alpha \times \sin \chi \times \cos (\beta-\beta s)+\sin \alpha \times \cos \chi
$$

where $\chi$ is slope (degrees), and $\beta s$ is aspect (degrees).

\subsubsection{Global radiation computation}

The hourly calculation of global radiation is obtained by the summation of direct (Rdir), diffuse (Rdiff) and reflected radiation (Rref) from surrounding terrain [18]:

$$
\text { Rdir }=S h \times \text { Rout } \tau^{\mathrm{M}} \cos i
$$

where $S h$ is a binary value of shadowing calculated for each hour and each integer value of solar altitude angle $(\alpha)$ and solar azimuth $(\beta)$ (Tab. I). Sh is calculated using the hillshade command in Arcinfo software, allowing to project a luminous ray of light from the calculated position of the sun on the DEM. When the cell is in the shadow of neighbouring slopes the value is 0 , otherwise it is 1 .

Modelling diffuse radiation is complex because irradiation is anisotropic, particularly under cloudy conditions. We assumed that diffuse radiation is isotropic $[10,30]$ and chose the model of Liu and Jordan [34]. This model takes into account solar altitude angle and transmissivity of the atmosphere under clear-sky conditions:

$$
\text { Rdiff }=\text { Rout } \times\left(0.271-0.294 \times \tau^{\mathrm{M}}\right) \times \sin \alpha .
$$

Terrain-reflected irradiance is calculated using Gate's formula [18]:

$$
\text { Rref }=r \times S c \times\left(0.271+0.706 \tau^{\mathrm{M}}\right) \times \sin \alpha \times \sin ^{2}(\chi / 2)
$$

where $r$ is the reflectance of the ground surface (we used a value of 0.2 ).

The summation of the three components gives global radiation (Rtot) for each hour of calculation $\left(\mathrm{W} / \mathrm{m}^{2}\right)$ :

$$
\text { Rtot }=\text { Rdir }+ \text { Rdiff }+ \text { Rref } .
$$

Daily values of global radiation are calculated by summation of hourly values from sunrise to sunset. Overcast sky $[11,23]$ are calculated using the cloud attenuation factor $(\mathrm{Kc})$ defined by Kasten and Czeplak [27]. This empirical equation is easy to use, requiring cloudiness measured in oktas, as generally observed in meteorological ground stations, each okta representing cloud cover of $1 / 8$ of the sky. A sufficient number of meteorological cloudiness ground measurements allow to interpolate them to obtain a spatially explicit information. Otherwise, gridded data sets are available for a large part of the world on the CRU website [39]. For France, we interpolated average values resulting from 30 years of daily measurements of 88 ground stations provided by Météo France, using the IDW method. We obtained a mean cloudiness grid for each month, at the same resolution as that of the DEM. Overcast radiation (Rtotc) was then calculated daily using the following equation:

$$
\begin{gathered}
\text { Rtotc }=\text { Rtot } \times K c \\
\text { Where } K c=\left(1-0.75(N / 8)^{3.4}\right)
\end{gathered}
$$

and where $N$ is cloudiness in oktas.

Global radiation can be calculated for durations from one day to one year, by summation of daily values over the period considered. This method is probably the most accurate, but is very costly in terms of computer time, and not well suited to calculations over large areas with high resolution and for long periods (monthly calculation, for example). To limit the calculation time, it is possible to estimate monthly solar radiation by extrapolating a limited number of daily calculations. In this case, the user defines a calculation interval, and the period is then divided into intervals of equal amplitude. For each interval, radiation is calculated for the median day and weighted by the number of days that it represents. This method reduces computing time, the daily variations being small in general.

\subsection{Data calculation and assessment}

The program Helios was run for the whole of France $\left(540000 \mathrm{~km}^{2}\right)$, using a digital elevation model with $50 \mathrm{~m} \times 50 \mathrm{~m}$ grid spacing. Solar radiation was calculated monthly and annually and mapped. To reduce computing time, monthly values were extrapolated from the median day for each of the 12 months.

The model was validated by comparing the data produced by Helios with those measured at meteorological stations of the Météo France network. We selected 88 weather stations scattered over the country, different from those used for the cloudiness calculations, located with an accuracy of $100 \mathrm{~m}$, and which have a minimum of 5 years of recording for each decade studied. The decadal values were collected over the period 1971-2002, and were aggregated to calculate monthly averages in order to be compared with GIS calculations. Errors generated by the interpolation to the entire month of a calculation achieved on a single day (the median of the month) were also evaluated. The quality of the model estimations was assessed by the absolute and relative mean differences between measured and Helios values, and by the correlation coefficient between these two values.

We also studied the sensitivity of the model according to conditions of slope, altitude, aspect, latitude, and cloudiness. We analysed the variability of radiation using the average values on the geographic area of calculation for all this environmental variables, except the one studied for which we changed its values with a specified interval, between its minimum and maximum. For example, to study latitude effect at national scale, we averaged values for slope, aspect, altitude and cloudiness, calculated for France, and made varying latitude from $41^{\circ}$ (min value) to $51^{\circ}$ (max value), by step of $1^{\circ}$. It corresponds to 11 simulations realised with Helios to make the solar radiation calculation for each degree of latitude. For altitude, we limited the test below $3000 \mathrm{~m}$, which is the limit of vegetation. The effect of scale was considered for three nested areas: the whole of France $\left(540000 \mathrm{~km}^{2}\right)$, the Lorraine region in northeastern France $\left(24000 \mathrm{~km}^{2}\right)$, and the Cornimont catchment in the Vosges mountains, northeastern France $\left(2.4 \mathrm{~km}^{2}\right)$.

\subsection{Use of calculated solar radiation in plant species distribution modelling}

A classical statistical method, stepwise logistic regression [35], was used to model plant species distribution in order to estimate if solar radiation calculated with Helios could improve vegetation models for large scale studies. Three forest species known to be sensitive to light were used: Abies alba, Acer pseudoplatanus, and Quercus pubescens. Abies alba (silver fir) is a 35-45 m coniferous tree, common in mountain ranges of France and Europe, and Acer pseudoplatanus (sycamore) is a $20-30 \mathrm{~m}$. deciduous tree, principally distributed in continental Europe and eastern France. These two species 


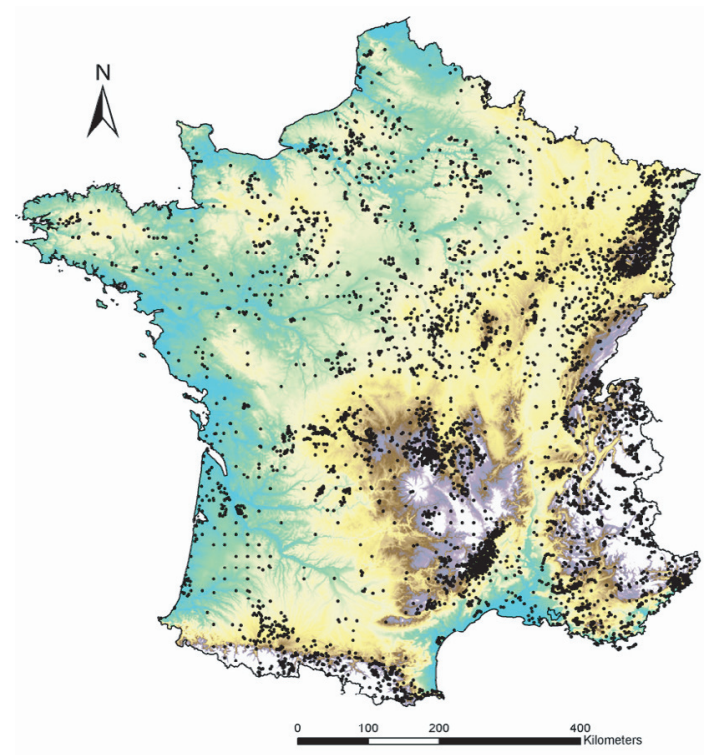

Figure 1. Location of the 6219 plots used to model plant species distribution.

are known to prefer atmospheric moisture [44]. Quercus pubescens (Pubescent Oak) is a 10-25 m sub-Mediterranean heliophilous and thermophilous tree, present in the southern two-thirds of France.

The presence/absence of these tree species was extracted from the EcoPlant [19] and Sophy [4] databases which store complete floristic inventories on plots scattered over France. The position of the plots is known within 10 to $1000 \mathrm{~m}$ precision. We used a sample of plots stratified according to latitude ( 3 strata: $41-48^{\circ}, 45-47.5^{\circ}, 47.5-51^{\circ}$ ), slope and aspect ( 3 strata: slope less than $5^{\circ}$, more than $5^{\circ}$ in north slope, more than $5^{\circ}$ in south slopes). The data set contains 6219 plots, with each of the 9 strata including 514 to 750 plots (Fig. 1). Plots too close to each other were eliminated in order to ensure a minimum distance of $1000 \mathrm{~m}$ between plots and thus avoid problems in distribution modelling linked to spatial autocorrelation.

For the three species, we evaluated the predictive ability of solar radiation. We compared distribution models realised without solar radiation values and others including Helios irradiation, considered alone or integrated in water balance calculations. In the first time, we modelled the species distribution according to four ecological variables relevant to characterisation of plant distribution [16, 38, 43, 49]: mean annual temperature (MaT), mean annual precipitation (MaP), altitude, and soil $\mathrm{pH}$. These variables were extracted from four GIS data layers: AURELHY model at $1 \mathrm{~km}^{2}$ resolution for MaT and $\mathrm{MaP}$ [2], DEM from the French Geographic Institute (IGN) at $50 \mathrm{~m}$ resolution for altitude, and $\mathrm{pH}$ from unpublished map elaborated with plant indicator values and used successfully to predict Acer campestre and Vaccinium myrtillus distribution [7,8]. Correlation between solar radiation and other variables used to model species distributions are poor: $R^{2}$ varies from 0.00094 for $\mathrm{MaP}$ to 0.066 for $\mathrm{pH}$, ensuring the absence of multicolinearity problems during the distribution modelling phase.

Logistic regression was used to elaborate the models with a forward stepwise procedure to select the most relevant of these variables. At each step, we selected the variable having the maximal residual deviance [8], tested with its quadratic form or if it not significant with the monotonic one $(p$-value $<0.001)$. The procedure was stopped when the adding of a new variable does not involve a significative increase of explained deviance, or when the remaining variables were not significant $(p<0.001)$. The quality of the model is characterised by explained deviance $\left(\mathrm{D}^{2}\right)$.

We then added to the initial candidate variables a supplementary one, in order to evaluate the direct correlation between modelled radiation and plant distribution, as well as its correlation through water balance, which is of crucial importance for plant distribution [1]. We compared effects of water balance calculated with the Thornthwaite formula (WBth), and water balance calculated with Turc's formula (Wbtu). These two water balance calculations obtained by substracting PET to precipitation are well known since a long time and largely used in ecological modelling [1]. WBth is calculated with a PET formula which uses only temperature values and latitude [46]. The computation of solar radiation, combined with temperature values, allows to use Turc PET formula to calculate WBtu [50]. We chose to calculate the value of the supplementary variable for June because of this month's importance for plant growth and distribution. The stepwise procedure was then run again including successively solar radiation, WBth and Wbtu, in complement to the initial Mat, MaP, altitude and soil $\mathrm{pH}$ variables.

\section{RESULTS}

Annual solar radiation values ranged from 1200 to $7200 \mathrm{MJ} / \mathrm{m}^{2}$, with a mean value near $4500 \mathrm{MJ} / \mathrm{m}^{2}$ (Fig. 2). The national map shows a latitudinal gradient with a radiation increase from north to south, with higher values in the Mediterranean area than on the Atlantic coast at the same latitude. The inset showing a little catchment in the Vosges mountains highlights the importance of topographic conditions on radiation in mountainous areas. For France, mean monthly values range between $880 \mathrm{MJ} / \mathrm{m}^{2}$ in July and $350 \mathrm{MJ} / \mathrm{m}^{2}$ in December. Maximum values are located on the southern slopes in the centre of the French Alps, and minimal values are both located in the north of France and on northern slopes in the mountains. The difference in radiation due to topography is as great in rugged mountains (cf. central Alps) as between the south and north of France.

\subsection{Validation of radiation model}

The 88 stations used for the validation range from 0 to $2780 \mathrm{~m}$ in altitude, from 0 to 38 degrees in slope, and cover all aspects. The annual radiation, obtained by summation of the monthly values from the GIS model, is strongly correlated with those measured by Météo France $\left(R^{2}=0.78\right)$, with a mean annual bias of $30.9 \mathrm{MJ} / \mathrm{m}^{2}$ (less than 1\%) (Fig. 3, Tab. II). The mean absolute error is $194.50 \mathrm{MJ} / \mathrm{m}^{2}$ for a mean global radiation value measured of $4450 \mathrm{MJ} / \mathrm{m}^{2} .67 \%$ of stations present a difference between annual measured and modelled values less than $5 \%$ of the measured values, and $93 \%$ show a difference of less $10 \%$, the maximum variation being $18 \%$. Ten of the stations giving the greatest underestimates are in the same region, in southeastern France (Fig. 3). The problem of radiation estimation in this area could be due to differences in reflectance for the soils of Mediterranean regions, 


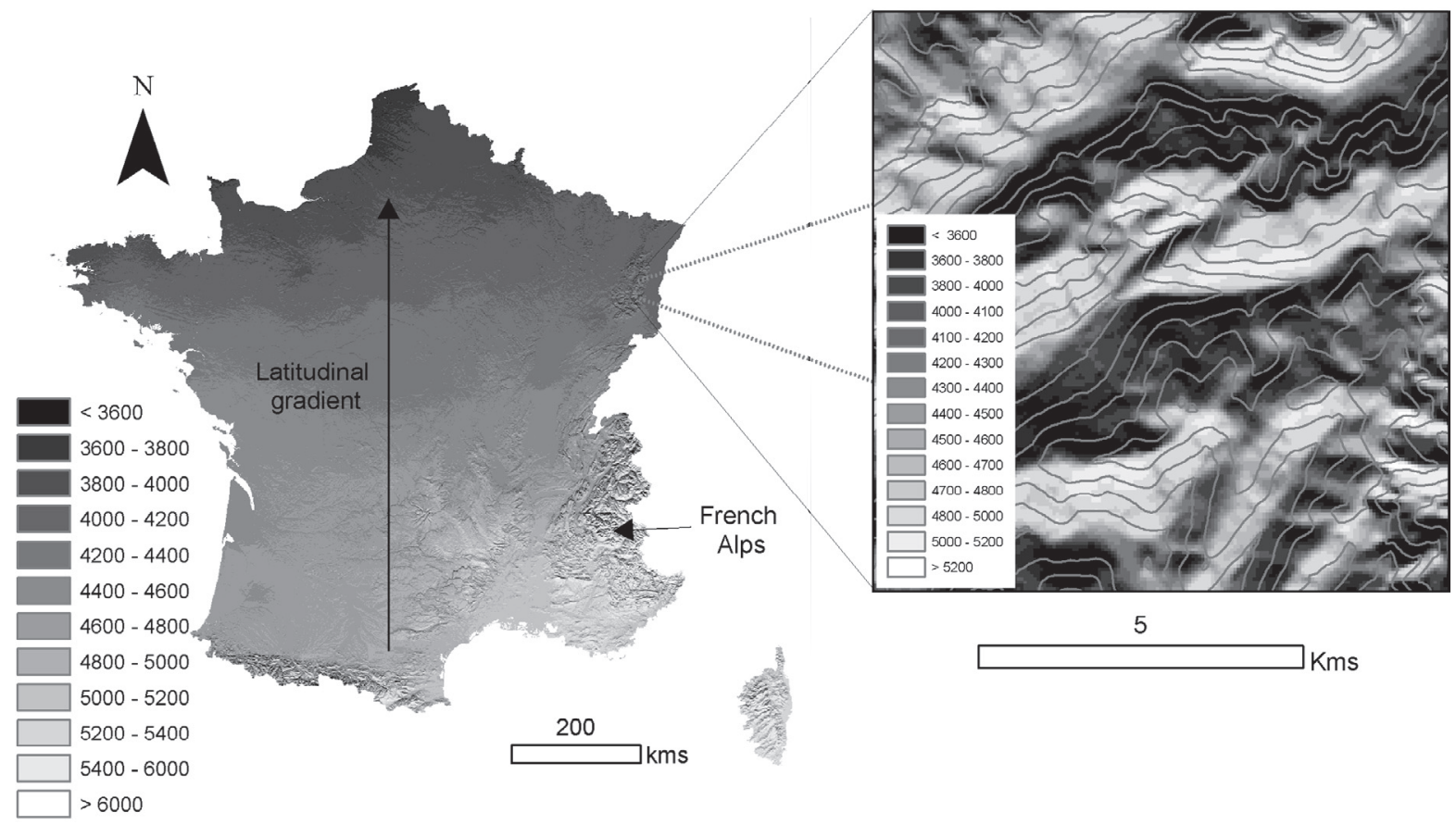

Figure 2. Annual solar radiation $\left(\mathrm{MJ} / \mathrm{m}^{2}\right)$ simulated with the Helios program in France, with an inset showing Cornimont catchment in the Vosges mountains.

Table II. Comparison of monthly and annual values of Helios radiation with 88 Météo France measurements $(\mathrm{MF})\left(\mathrm{MJ} / \mathrm{m}^{2}\right)$.

\begin{tabular}{lccccccccccccc}
\hline & January & February & March & April & May & June & July & August & September & October & November & December & Annual \\
\hline MF & 128.7 & 190.9 & 350.1 & 454.8 & 582.6 & 619.3 & 648.5 & 571.6 & 397.4 & 253.9 & 147.0 & 105.4 & 4450.2 \\
Helios & 111.7 & 174.0 & 336.9 & 467.6 & 606.0 & 661.2 & 681.5 & 580.5 & 401.7 & 239.8 & 128.9 & 91.5 & 4481.2 \\
Bias & -17.0 & $-16,9$ & -13.2 & 12.8 & 23.4 & 41.9 & 33 & 8.9 & 4.3 & -14.1 & -18.1 & -13.9 & 30.9 \\
$R^{2}$ & 0.88 & 0.84 & 0.81 & 0.60 & 0.60 & 0.62 & 0.68 & 0.65 & 0.72 & 0.78 & 0.84 & 0.88 & 0.78 \\
\hline
\end{tabular}

or an overestimation of cloudiness. For all stations, the examination of monthly values shows a summer overestimation and a winter underestimation of the model as compared to the measured data, the bias being reduced for the two equinoxes (Tab. II). The correlation between the model and the measured values is better in winter $\left(R^{2}=0.88\right.$ in December or January, the lowest $R^{2}$ being 0.60 in April or May).

We tested the Helios model using data from eleven measured ground stations with a slope of more than $5^{\circ}$ (maximum value $=38^{\circ}$, mean value $=14^{\circ}$ ). These stations have a mean absolute error of $305 \mathrm{MJ} / \mathrm{m}^{2}$ for a mean annual global radiation of $4417 \mathrm{MJ} / \mathrm{m}^{2}$, which can be compared to $194.5 \mathrm{MJ} / \mathrm{m}^{2}$ for all ground stations. However, it was not possible to link mean absolute error with slope $(p>0.05)$. This logical slight increase in error could be explained by the complexity of calculation in rugged areas, the fine scale variation of cloudiness (effect of valleys or tops), and the precision of localisation of meteorological stations $(100 \mathrm{~m})$. The second limitation is the DEM resolution $(50 \mathrm{~m})$, which could average microtopographic changes and modify slope and aspect values.

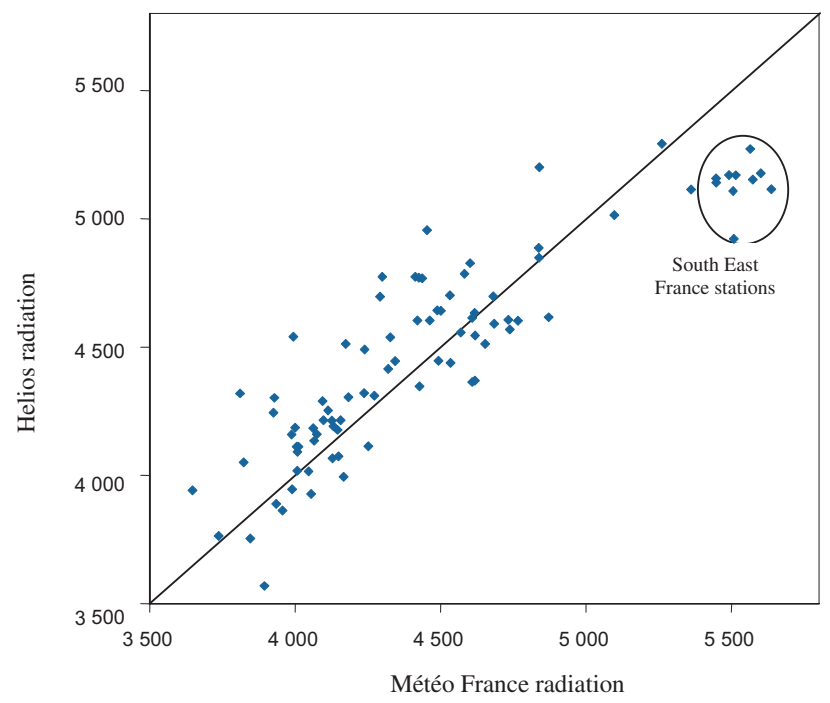

Figure 3. Relationship between annual solar radiation measured at Météo France stations and Helios values $\left(\mathrm{MJ} / \mathrm{m}^{2}\right)$. 

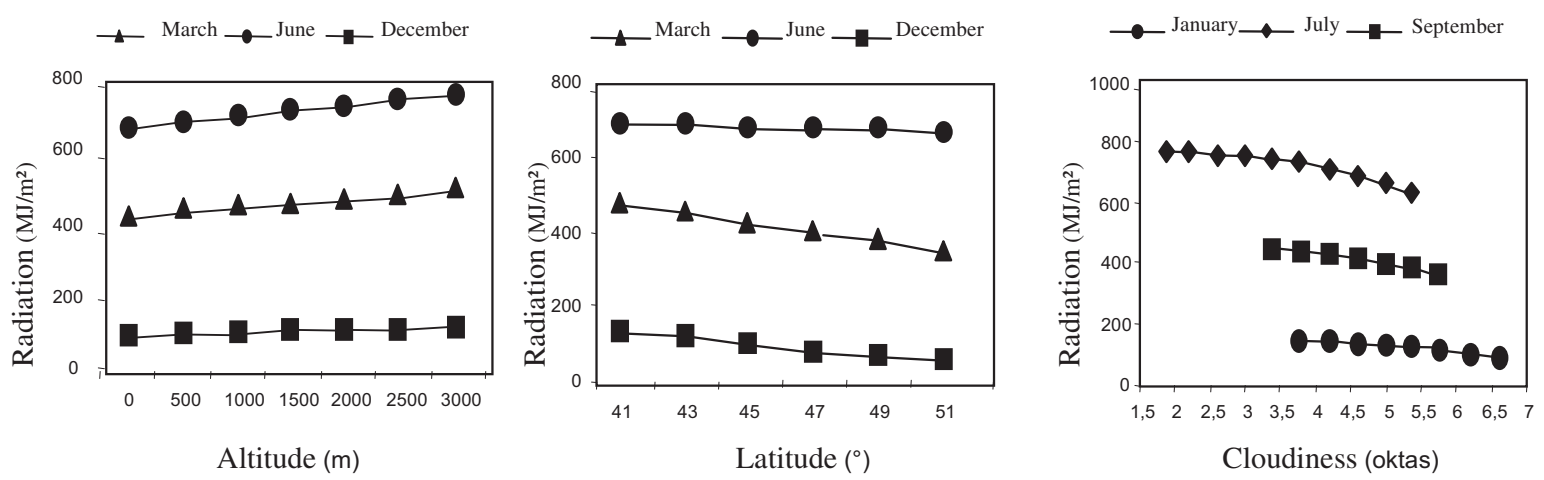

Figure 4. Variation of solar radiation for different conditions of altitude, latitude, and cloudiness $\left(\mathrm{MJ} / \mathrm{m}^{2}\right)$.

This GIS calculation, done for the median day and extrapolated to the month, does not show sizeable variation as compared to the monthly values obtained from the summation of all days of the month. The test made for 17 weather stations for March showed an average difference with measured value of $19.92 \mathrm{MJ} / \mathrm{m}^{2}$ with the one-day calculation and $19.69 \mathrm{MJ} / \mathrm{m}^{2}$ for the 30-day calculation. It is thus possible to calculate radiation over long periods using only the median day, which is quicker and sufficiently accurate. On the scale of France, the comparison with another origin of cloudiness (CRU data, [39]) shows locally important differences. For example, we have about 1.20 oktas of variation for June with CRU data, in southwestern France, involving more than $11 \%$ of radiation differences, with worse results when using CRU cloudiness.

\subsection{Sensitivity analysis}

We characterised the relationship between the calculated global radiation and slope, aspect, altitude, latitude and cloudiness. An increase in cloudiness or latitude involves a decrease in radiation, while high altitudes receive more radiation than lower ones. For June, the difference in latitude between the south and north of France (approximately $10^{\circ}$ ) compensates for an elevation of $700 \mathrm{~m}$ on radiation values: both involve a change of about $20 \mathrm{MJ} / \mathrm{m}^{2}$ (Fig. 4). The relationships between altitude or latitude and radiation are both almost linear. An increase of $100 \mathrm{~m}$ in altitude involves an increase in radiation of $4.4 \mathrm{MJ} / \mathrm{m}^{2}$ in December and $14.7 \mathrm{MJ} / \mathrm{m}^{2}$ in June. Radiation values decrease naturally with latitude, this drop being greater at the equinoxes and smaller at the solstices, mainly at the summer solstice. For example, radiation decreases about $12.2 \mathrm{MJ} / \mathrm{m}^{2}$ per degree of latitude for March, and $2.7 \mathrm{MJ} / \mathrm{m}^{2}$ per degree of latitude for June.

We tested variations of cloudiness for three months. January presents the maximum values of nebulosity (between 3.8 oktas and 6.6 oktas), July is the lowest cloudiness month (between 1.9 and 5.3 oktas), and September presents intermediate values (between 3.3 to 5.7 oktas). An increasing nebulosity between the two extremes recorded at the study site leads to a decrease for radiation of $18.3 \mathrm{MJ} \backslash \mathrm{m}^{2}$ per okta for January, $31.0 \mathrm{MJ} \backslash \mathrm{m}^{2}$ per okta for July, and $39.2 \mathrm{MJ} \backslash \mathrm{m}^{2}$ per okta for

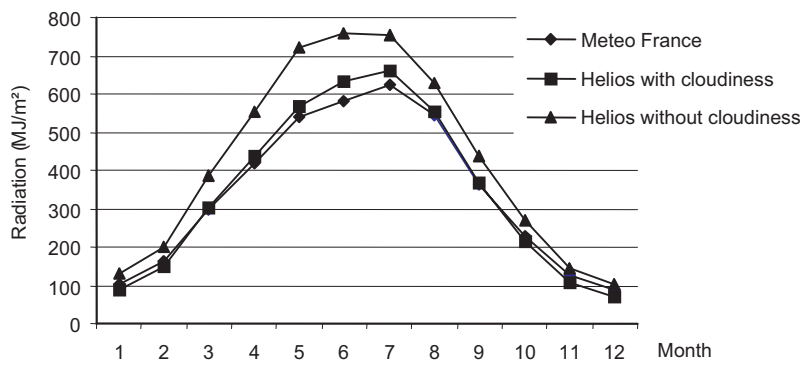

Figure 5. Solar radiation calculated with Helios with and without cloudiness for the Luxeuil Meteorological station.

September (Fig. 4). Taking into account cloudiness in the calculations improves the model considerably, mainly in the north of France, which is cloudier, as we can see at the representative Météo France ground station of Luxeuil ( $47^{\circ} 47^{\prime} 12^{\prime}$ ' N, $6^{\circ} 21^{\prime} 54^{\prime \prime} \mathrm{E}, 271 \mathrm{~m}$ altitude, yearly average cloudiness $5.5 \mathrm{ok}-$ tas) (Fig. 5). For the 88 meteorological ground stations, use of cloudiness values decreases average solar radiation from $21 \%$ for December and January to 9\% for August.

Change in radiation values following the increase in slope depends simultaneously on aspect and the period concerned (Fig. 6). An increase in slope corresponds to a decrease in radiation for east and west aspects $\left(90\right.$ or $270^{\circ}$ ), and particularly for northern exposure. For the southern aspect, an increase in slope is linked to an increase in radiation in winter and to an initial increase followed by a decrease in radiation after $45^{\circ}$ of slope in March and $30^{\circ}$ in June, caused by the high position of the sun. Radiation variations according to aspect are sizeable for the highest slopes: for March, radiation ranges from 1 to 9 for a slope of $50^{\circ}$, and from 1 to 2 for a slope of $20^{\circ}$. The most important radiation variations due to the slope are observed for northern exposure: for example, the change in slope from 0 to $80^{\circ}$ in June involves a division by 4 , while the division is by 2 for southern exposure.

However, radiation values are not distinguished by the same parameters for different scales. At a scale of a small study site, such as the Cornimont catchment area $\left(2.4 \mathrm{~km}^{2}\right)$, the local parameter changes in topography (slope, aspect, and to a lesser extent, altitude), explain the diversity of radiation values (Tab. III). The larger the surface of calculation, the more the 

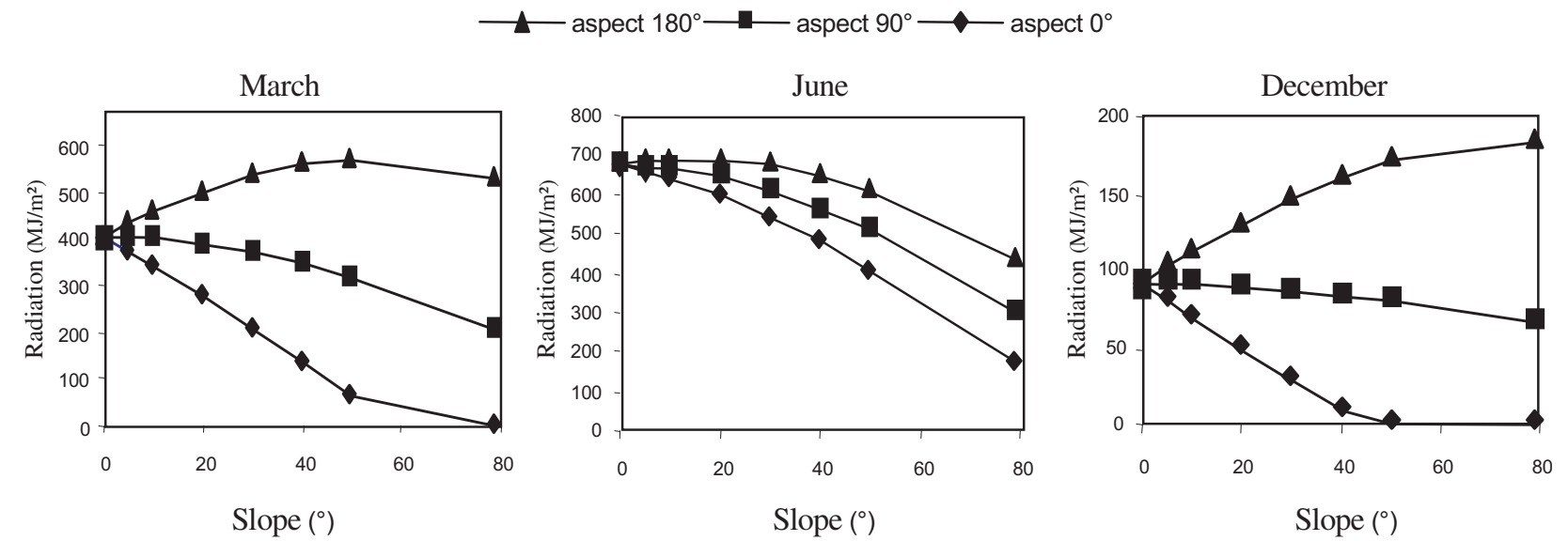

Figure 6. Variation of radiation with slope and aspect $\left(\mathrm{MJ} / \mathrm{m}^{2}\right)$.

Table III. Amplitude of radiation values $\left(\mathrm{MJ} / \mathrm{m}^{2}\right)$ obtained while varying successively each model parameter between it two extremes values for three nested areas. Altitude is limited to $3000 \mathrm{~m}$, and slope to $40^{\circ} . \mathrm{N}=$ not observed.

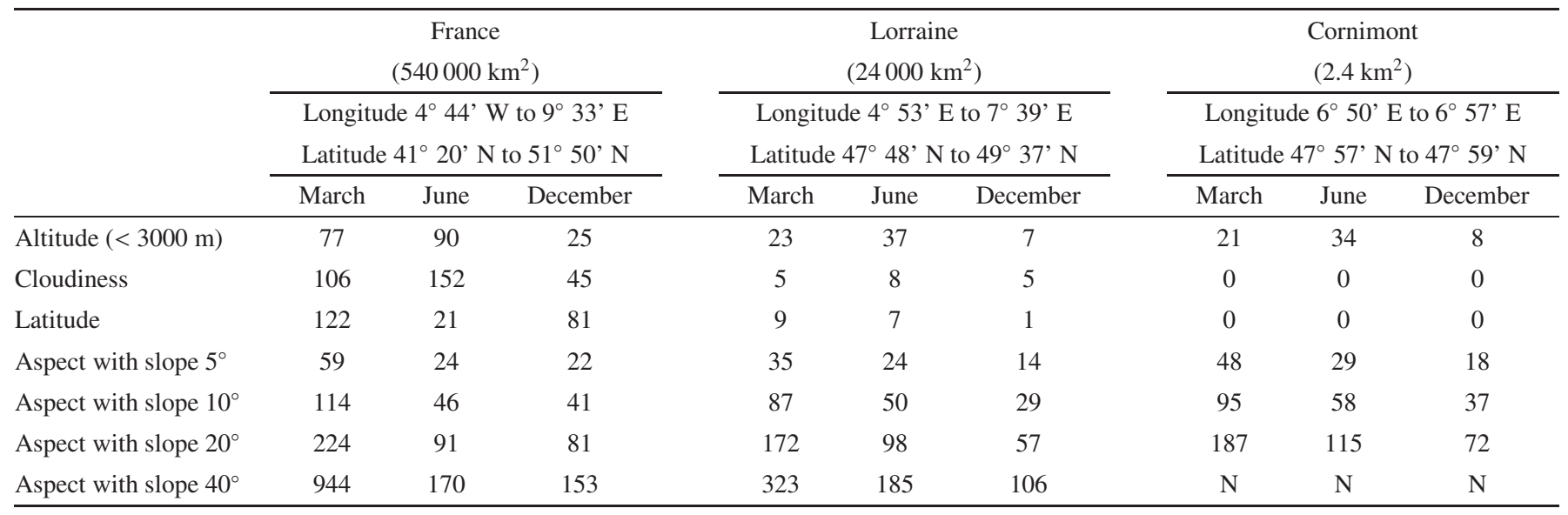

effect of global parameter (latitude and cloudiness) increases, becoming more significant than altitude and aspect on gentle slopes in explaining the diversity of radiation values. For example, for gentle slopes $\left(5^{\circ}\right)$, the effect of latitude or cloudiness is most important than topography effect at the scale of France for March. However, for steep slopes (approximately $40^{\circ}$ ), aspect is the parameter involving the greatest radiation change on the scale of France. The incidence of parameter variations on radiation is also dependent on the time of year. This is particularly true for aspects with high slope, and latitude, which is more important in March, and for cloudiness, which has a greater effect in June, for large territories.

\subsection{Large scale plant distribution modelling using solar radiation}

The distribution modelling highlights a significant effect $(p<0.001)$ of calculated radiation for the three studied species. The $\mathrm{D}^{2}$ with univariate radiation models reach 0.043 , 0.018 and 0.100 for Acer pseudoplatanus, Abies alba, and
Quercus pubescens, respectively. Temperature and precipitation are the most important variables in predicting the distribution of Acer pseudoplatanus and Abies alba, and $\mathrm{pH}$ is most important in predicting distribution of Quercus pubescens, according to the deviance criterion. Including solar radiation in the initial Altitude-MaT-MaP-pH model involves a significant increase in $\mathrm{D}^{2}$ for the three studied species (Tab. IV). The response of Acer pseudoplatanus and Abies alba to solar radiation is decreasing, and the response of Quercus pubescens is increasing, according to knowledge of these species [44]. Solar radiation acts in complement to other climatic or soil variables to explain these tree species distributions. The effect of water balance calculated using the Thornthwaite formula is significant for each species but it is systematically lower than the effect of water balance calculated with Turc's formula including solar radiation modelled with Helios (Tab. IV).

Each model was improved by addition of solar radiation, directly or included in water balance calculated with Turc's formula. The best results without radiation were obtained using WBth (respectively $\mathrm{D}^{2}$ 0.197, 0.347 and 0.337 for Acer pseudoplatanus, Abies alba, and Quercus pubescens). When 
Table IV. Occurrence of Acer pseudoplatanus, Abies alba, and Quercus pubescens $(n=6219)$, and explained deviance $\left(\mathrm{D}^{2}\right)$ for the models of distribution. June solar radiation ( $\mathrm{rad6}), \mathrm{pH}$, mean annual temperature (MaT), mean annual precipitation (MaP), altitude (Alt), June Thornthwaite and Turc water balance (WBth6, WBtu6) are used depending on the models.

\begin{tabular}{lccc}
\hline Species & Acer pseudoplatanus & Abies alba & Quercus pubescens \\
\hline Occurence & 819 & 1172 & 905 \\
rad6 & 0.043 & 0.018 & 0.100 \\
pH, MaT, MaP, DEM & 0.184 & 0.332 & 0.328 \\
pH, MaT, MaP, DEM + rad6 & 0.217 & 0.352 & 0.343 \\
pH, MaT, MaP, DEM + WBth6 & 0.197 & 0.347 & 0.337 \\
pH, MaT, MaP, DEM + WBtu6 & 0.235 & 0.364 & 0.358 \\
\hline
\end{tabular}

solar radiation is available, the best models used WBtu and $\mathrm{D}^{2}$ increased to $0.235,0.364$, and 0.358 for the same three species.

\section{DISCUSSION, CONCLUSION}

Models using precise solar radiation taking topographical characteristics into account are generally carried out on a local to regional scale $[37,40]$, but not on a larger scale, such as a country or continent $[48,51]$, due to the difficulty of calculating accurate data. Also, solar radiation is rarely used to model plant distribution over large territories.

We elaborated the Helios program, necessiting few input parameter largely available over the world, in order to calculate fine resolution spatially distributed solar radiation over large areas, with good accuracy. Helios, checked for France by comparing model outputs with data measured at weather stations, distinguished both global variability and local topographic conditions, which is not possible directly with interpolations from weather station or with layers provided by satellite imagery [23]. We showed by a sensitivity analysis the importance of each one of these components depending of the scale, topographical effects having a major effect until regional scale, but requiring to be combined with latitude and cloudiness beyond.

The tests carried out stressed the importance of cloudiness to limit bias of radiation estimations at broad scale. Mean annual overestimation of the calculated radiation was $0.7 \%$ for the 88 weather stations used with the overcast model, and $17.25 \%$ with the clear sky model. Cloudiness improves consequently the model despite the few meteorological stations used for interpolation. In our study, the interpolated ground measurements from a meteorological network are more efficient than CRU data [39], that can nevertheless be used if no meteorological station data are available.

It is difficult to compare the results of this calculation with data from other studies because of the lack of published validation for many models, and the important differences in methodology for the others. Reuter et al. [45] calculated differences between measured values and simulated irradiance with the SRAD model for two weather stations in Germany, with differences of $6.34 \%$ and $7.31 \%$ for July, compared with $5.09 \%$ for the July average of the 88 weather stations used in this study. Kang et al. [26] also compared the results of three different models with 5 weather stations located in Korea and obtained a $16.8 \%$ underestimation for the annual values with one model and an overestimation of respectively $20 \%$ and $1.6 \%$ for the two other models, compared with a $0.7 \%$ overestimation by Helios in our study. Nevertheless, calculations should be done at the same place, with the same protocol and with the same ground control points to compare the effectiveness of different models.

Helios is suited to large-scale plant distribution studies: it enhanced directly or indirectly, through water balance, the predictive performance of the models for the three species studied. Using solar radiation in water balance based on Turc formula for PET calculation seems to be more effective than its use alone. The efficiency of this index is confirmed by its successful used in tree growth prediction [42]. The spatiallydistributed nature of information provided by Helios allows to include solar radiation in predictive distribution maps of plant species.

The model could be improved in different ways. The amount of clouds may vary in short distances, particularly in rugged terrain where we shown radiation estimations are less well estimated than elsewhere. A refinement of spatial and temporal cloudiness variability could be a major improvement, using satellite cloud measurements for example. The quality of the DEM is also important: errors in slope and aspect values as well as DEM resolution can generate significant differences in results. Make varying albedo depending of soil cover and season instead of the use of a constant value should also improve evaluation of terrain-reflected irradiance, particularly in mountainous areas where snow coverage has a high albedo, or in Mediterranean regions where the vegetation cover is discontinuous and the solar radiation systematically under-estimated. However, the estimation of this variable requires precise information about land cover, difficult to obtain at fine resolution. The best numerical data available for Europe is the $1 \mathrm{~km}^{2}$ gridded Corine Land Cover layer. It could be possible to estimate values of albedo per vegetation units, or to directly use albedo values recorded by remote sensing. The estimation of radiation at soil level under forest cover could also be developed, for example using locally hemispherical viewshed or a Lidar DEM to obtain spatial information about tree shadowing.

Plant distribution modelling require to work over large territories, the extent of the study site should range beyond the 
observed environmental limits of the species distribution to identify all the conditions the species can live. However, large scale models generally don't take into account topography effect which is an important driver of ecological processes that acts as a local filter, allowing to distinguish favourable from unfavourable habitats inside the species range areas. Also, producing ecological GIS layers describing finely biophysical factors over large territories is an important stake in the next years. Our work allows to produce fine resolution solar radiation maps, and, by combination with other climatic data, to derived drought indices, easy to use for plant ecologists from local to large scale. These data allow to improve spatial distribution models and species behaviour analysis, an information particularly useful for ecosystem management in the actual global change context.

Acknowledgements: The authors wish to thank the anonymous reviewers for their valuable comments. This study was carried out with financial support from the Forest Ecosystems public-interest group (GIP-ECOFOR).

\section{REFERENCES}

[1] Austin M.P., Spatial prediction of species distribution: an interface between ecological theory and statistical modelling, Ecol. Model. 157 (2002) 101-118.

[2] Benichou P., Le Breton O., Prise en compte de la topographie pour la cartographie des champs pluviométriques statistiques, La Météorologie 7 (1987) 23-34.

[3] Brang P., Von Felten S., Wagner S., Morning, noon, or afternoon: does timing of direct radiation influence the growth of Picea abies seedlings in mountain forests? Ann. For. Sci. 62 (2005) 697-705.

[4] Brisse H., de Ruffray P., Grandjouan G., Hoff M., European vegetation survey. The phytosociological database "Sophy". Part 1. Calibration of indicator plants. Part 2. Socio-ecological classification of the relevés, Ann. Bot. 53 (1995) 177-223.

[5] Campbell G.S., Fundamentals of radiation and temperature relations, in: Lange O.L., Nobel P.S., Osmond C.B., Ziegler H. (Eds.), Physiological plant ecology I: Responces to the physical environment, Encyclopedia of plant physiology 12A, Springer New York, 1981, pp. 11-40.

[6] Cooper P.I., The absorption of solar radiation in solar stills, Sol. Energy 12 (1969).

[7] Coudun C., Gégout J.C., Quantitative prediction of the distribution and abundance of Vaccinium myrtillus (L.) with climatic and edaphic factors in french forests, 48th IAVS Symposium, Lisbonne, 2005, pp. 1-19.

[8] Coudun C., Gégout J.C., Piedallu C., Rameau J.C., Soil nutritional factors improve models of plant species distribution: an illustration with Acer campestre (L.) in France, J. Biogeogr. 33 (2006) 1750-1763.

[9] Davis F., Goetz S., Modeling vegetation pattern using digital terrain data, Lands. Ecol. Vol. 4, No. I, 1990, pp. 69-80.

[10] Dubayah R., Modelling a solar radiation topoclimatology for the Rio Grande river basin, J. Veg. Sci. 5 (1994) 627-640.

[11] Dubayah R., Loechel S., Modeling topographic solar radiation using GOES data, J. Appl. Meteorol. 36 (1997) 141-154.

[12] Dubayah R., Rich P.M., Topographic solar-radiation models for GIS, International J. Geogr. Inf. Syst. 9 (1995) 405-419.

[13] Dubayah R., Vankatwijk V., The topographic distribution of annual incoming solar-radiation in the Rio-Grande river basin, Geophys. Res. Lett. 19 (1992) 2231-2234.
[14] Duguay C.R., Radiation modelling in mountainous terrain: review and status, Mount. Res. Dev. 13 (1993) 339-357.

[15] Elith J., Graham C.H., Anderson R.P., Dudik M., Ferrier S., Guisan A., Hijmans R.J., Huettmann F., Leathwick J.R., Lehmann A., Li J., Lohmann L.G., Loiselle B.A., Manion G., Moritz C., Nakamura M., Nakazawa Y., Overton J.M., Peterson A.T., Phillips S.J., Richardson K., Scachetti-Pereira R., Schapire R.E., Soberon J., Williams S., Wisz M.S., Zimmermann N.E., Novel methods improve prediction of species' distributions from occurrence data, Ecography 29 (2006) 129-151.

[16] Franklin J., Predictive vegetation mapping: Geographic modelling of biospatial patterns in relation to environmental gradients, Prog. Phys. Geogr. 19 (1995) 474-499.

[17] Fu P., Rich P.M., A geometric solar radiation model and its applications in agriculture and forestry, Comput. Electron. Agric. 2003 (2002) 25-35.

[18] Gates D.M. (Ed.), Biophysical Ecology New York, 1980.

[19] Gégout J.C., Coudun C., Bailly G., Jabiol B., EcoPlant: a forest site database linking floristic data with soil and climate variables, J. Veg. Sci. 16 (2005) 257-260.

[20] Guisan A., Thuiller W., Predicting species distribution: offering more than simple habitat models, Ecol. Lett. 8 (2005) 993-1009.

[21] Guisan A., Zimmermann N.E., Predictive habitat distribution models in ecology, Ecol. Model. 135 (2000) 147-186.

[22] Hetrick W.A., Rich P.M., Barnes F.J., Weiss S.B., GIS-based solar radiation flux models. GIS, Photogrammetry and Modeling 3: 13243. American Society for Photogrammetry and Remote Sensing, Technical papers GIS Photogrammetry and Modelling, Vol. 3, 1993, pp. 132-143.

[23] Hofierka J., Suri M., The solar radiation model for Open source GIS: implementation and applications (2002), Open source GIS GRASS User conference 2002, Trento, Italy, 2002.

[24] Horsch B., Modelling the spatial distribution of montane and subalpine forests in the central Alps using digital elevation models, Ecol. Model. 168 (2003) 267-282.

[25] Huld T.A., Š́ri M., Dunlop E.D., GIS-based estimation of solar radiation and PV generation in central and eastern Europe on the web., 9th EC-GI\&GIS Workshop, Coruña, Spain, 2003.

[26] Kang S.Y., Kim S., Lee D., Spatial and temporal patterns of solar radiation based on topography and air temperature, Can. J. For. Res. J. Can. Rech. For. 32 (2002) 487-497.

[27] Kasten F., Czeplak G., Solar and terrestrial radiation dependent of the amount and type of cloud, Sol. Energy 24 (1980) 177-189.

[28] Kreith F., Kreider J.F., Principles of solar engineering, Hemisphere Publishing Corp., Washington DC, 1978.

[29] Kumar L., Skidmore A., Radiation-vegetation relationships in a Eucalyptus forest, Photogramm. Eng. Remote Sens. 66 (2000) 193204.

[30] Kumar L., Skidmore A.K., Knowles E., Modelling topographic variation in solar radiation in a GIS environment, Int. J. Geogramm. Inf. Sci. 11 (1997) 475-497.

[31] Lebourgeois F., Climatic signal in annual growth variation of silver fir (Abies alba Mill.) and Spruce (Picea abies Karst) from the French permanent plot network (RENECOFOR), Ann. For. Sci. 64 (2007) 333-343.

[32] Lehmann A., Leathwick J.R., Overton J.M., Assessing New Zealand fern diversity from spatial predictions of species assemblages, Biodiv. Conserv. 11 (2002) 2217-2238.

[33] List R.J., Smithsonian Meteorological Tables, 6th rev. ed., Smithsonian Institution, Washington DC, USA, 1984.

[34] Liu B.Y., Jordan R.C., The interrelationship and characteristic distribution of direct, diffuse and total solar radiation, Sol. Energy 4 (1960) 1-19.

[35] McCullagh P., Nelder J.A., Generalized linear models, Chapman \& Hall, London, UK, 1997. 
[36] Meentemeyer R.K., Moody A., Franklin J., Landscape-scale patterns of shrub-species abundance in California chaparral: The role of topographically mediated resource gradients, Plant Ecol. 156 (2001) 19-41.

[37] Miller J., Franklin J., Modeling the distribution of four vegetation alliances using generalized linear models and classification trees with spatial dependence, Ecol. Model. 157 (2002) 227-247.

[38] Moser D., Dullinger S., Englisch T., Niklfeld H., Plutzar C., Sauberer N., Zechmeister H.G., Grabherr G., Environmental determinants of vascular plant species richness in the Austrian Alps, J. Biogeogr. 32 (2005) 1117-1127.

[39] New M., Hulme M., Jones P., Representing twentieth-century space-time climate variability. Part I: Development of a 1961-1990 mean monthly terrestrial climatology, J. Clim. 12 (1999) 829-856.

[40] Ohmann J.L., Gregory M.J., Predictive mapping of forest composition and structure with direct gradient analysis and nearest-neighbor imputation in coastal Oregon, USA, Can. J. For. Res. 32 (2002) 725-741.

[41] Oke T.R., Boundary layer climates, Methuen, NY, USA, 1987.

[42] Pinto P., Gégout J.C., Hervé J.C., Dhôte J.F., Changes in environmental controls of Abies alba growth in Vosges mountains during the twentieth century, Glob. Ecol. Biogeogr. 16 (2007) 472-484.

[43] Pinto P.E., Gegout J.C., Assessing the nutritional and climatic response of temperate tree species in the Vosges mountains, Ann. For. Sci. 62 (2005) 761-770.

[44] Rameau J.C., Mansion D., Dumé G., Flore forestière française guide écologique illustré - tome 2: Montagnes, Institut pour le Développement, Paris, 1993.
[45] Reuter H.I., Kersebaum K.C., Wendroth O., Modelling of solar radiation influenced by topographic shading - evaluation and application for precision farming, Phys. Chem. Earth 30 (2005) 143-149.

[46] Rich P., Hetrick W., Savings S., Modelling topographical influences on solar radiation: manual for the solarflux model, Los Alamos national laboratories, Los Alamos, USA, 1995.

[47] Thornton P.E., Hasenauer H., White M.A., Simultaneous estimation of daily solar radiation and humidity from observed temperature and precipitation: An application over complex terrain in Austria, Agric. For. Meteorol. 104 (2000) 255-271.

[48] Thuiller W., Lavorel S., Araujo M.B., Sykes M.T., Prentice I.C., Climate change threats to plant diversity in Europe, Proceedings of the National Academy of Sciences of the USA 102 (2005) 82458250 .

[49] Thuiller W., Vayreda J., Pino J., Sabate S., Lavorel S., Gracia C., Large-scale environmental correlates of forest tree distributions in Catalonia (NE Spain), Glob. Ecol. Biogeogr. 12 (2003) 313-325.

[50] Turc L., Evaluation des besoins en eau d'irrigation et évaporation potentielle, Ann. Agron. 12 (1961) 13-49.

[51] Turner M.G., Gergel S.E., Dixon M.D., Miller J.R., Distribution and abundance of trees in floodplain forests of the Wisconsin river: Environmental influences at different scales, J. Veg. Sci. 15 (2004) 729-738.

[52] Van Dam O., Forest filled with gaps : effects of gap size on water and nutrient cycling in tropical rain forest: a study in Guyana, Université d'Utrecht, The Netherlands, 2001, p. 208.

[53] Wilson J.P., Gallant J.C., Terrain analysis, principles and applications, John Wiley and sons, 2000. 